\title{
ANÁLISE AMBIENTAL DO CÓRREGO ARROZ DOCE SELVIRIA/MS.
}

\author{
Rony Blini ${ }^{1}$ \\ Arnaldo Yoso Sakamoto ${ }^{2}$
}

RESUMO: A utilização dos recursos hídricos pelos seres humanos, dentre eles os sistemas lacustres, envolve modificações das condições naturais da bacia hidrográfica. $\mathrm{O}$ desenvolvimento das ações antrópicas, responsável por essas alterações, sobre o sistema natural envolvem várias etapas e caminhos, desde as nascentes, e o impacto sobre o seu curso. O objetivo é verificar a ausência de água em algumas propriedades ao longo do córrego Arroz Doce. A metodologia foi de observação in loco e o uso das novas tecnologias como geoprocessamento e georreferenciamento e o diagnóstico da paisagem da nascente e durante seu curso no córrego arroz doce no municipio de Selvíria. Concluise que a integração dos elementos naturais ao longo do trajeto do Córrego, e a interferência do homem, e as transformações ao longo do tempo ocorreu uma eutrofização, sendo viável um planejamento de recuperação da área do córrego uma vez que o mesmo serve de abastecimento a várias propriedades.

PALAVRAS-CHAVE: Recursos hídricos. Geotecnologias. Eutrofização. Córrego Arroz Doce. Selvíria.

\section{INTRODUÇÃO}

As práticas associadas ao ordenamento e ao planejamento do território são observadas desde a antiguidade, e a preocupação com a qualidade de vida da população

\footnotetext{
${ }^{1}$ Mestrando. Universidade Federal de Mato Grosso do Sul. Programa de Pós-Graduação em Geografia. Campus de Três Lagoas - MS (PPGEO - UFMS/CPTL).

${ }^{2}$ Professor Doutor Docente da Disciplina: Análise Ambiental e Planejamento. Oferecida pelo Programa de Pós-Graduação em Geografia- Universidade Federal de Mato Grosso do Sul. Campus de Três Lagoas - MS.
} 
e a eminência da escassez de recursos colaboraram para a retomada de estruturas de planejamento urbanos e regionais na concepção holística, integradora e ambiental.

Segundo Christofoletti, o planejamento ambiental envolve-se com os programas de utilização dos sistemas ambientais, como elemento condicionante de planos nas escalas espaciais do local, regional e nacional, uso do solo rural, execução de obras de engenharia e planejamento econômico. Em função de focalizar os ecossistemas e os geossistemas (sistema físico), os seus objetivos podem sublinhar perspectivas ecológicas e geográficas (CHRISTOFOLETTI, 1999, p.162).

A descrição de bacia segundo Teixeira et al. (2000) rios, no sentido geral, são cursos naturais de água doce, com canais definidos e fluxo permanente ou sazonal, lago ou rio dada a sua transformação da paisagem, agindo continuamente no modelado do relevo. Conscientes de que na bacia a água é um ponto central e unânime no debate sobre a sustentabilidade, e de que, historicamente, vem se provando o papel fundamental das florestas na administração deste recurso na biosfera. A floresta da mata ciliar cumpre uma função fundamental na interceptação, infiltração e administração da umidade no solo, abastecendo os lençóis e aquíferos que, por sua vez, brotam na forma de nascentes que formam os corpos d'água.

As bacias hidrográficas integram uma visão de conjunto do comportamento das condições naturais e atividades humanas nelas desenvolvidas uma vez que, mudanças significativas em qualquer dessas unidades, podem gerar alterações, efeitos e/ou impactos a jusante e nos fluxos energéticos de saída (descarga, cargas sólidas e dissolvida) (GUERRA, 1998, p.353).

A partir da analise da Teoria Geral dos Sistemas de Bertalanffy (1977), considerase, a análise desenvolvida a partir desta metodologia é primordial para reconhecimento de áreas de ambientes que sofrem muito com os processos de alteração do ambiente. São medidas inicias que incentivam políticas que tenham como objetivo o planejamento e a gestão do território. Quando efetuado com medidas de curto e longo prazo podem possibilitar o uso adequado da natureza podendo viabilizar atividades econômicas e de conservação territorial. Segundo Silva (2003):

O planejamento é uma atividade contínua. Embora possa ser necessário planejar por um período de tempo específico, ele deve ser constantemente monitorado e revisado e, se apropriado, estender para outros períodos do planejamento. O 
processo de planejamento exige uma abordagem interdisciplinar, envolve diferentes projetos específicos (um ou mais programas) e áreas geográficas pré-definidas (SILVA, 2003, p.5-6).

A Lei Federal 9.433, de 8 de Janeiro de 1997, adotou a Bacia Hidrográfica como unidade de estudo e planejamento. Um eficiente modelo territorial para esta análise e políticas de planejamento são as Bacias Hidrográficas, pois esta não possui seus limites determinados politicamente, podendo abarcar uma gama maior de fenômenos que ocorrem no ambiente natural e ou eutrofizado.

O Distrito de Selvíria localiza-se no município de Três Lagoas. Elevado à categoria de município com a denominação de Selvíria, pela lei estadual oㅡ 79, de 12-05-1980, desmembrado dos municípios de Três Lagoas e Inocência. Sede no atual distrito de Selvíria (ex-localidade). Constituído do distrito sede. Instalado em 16-06-1981. Em divisão territorial datada de 1-VII-1983, o município é constituído do distrito sede. Assim permanecendo em divisão territorial datada de 2009. A população em 2010 é de 6.287; área da unidade territorial $\left(\mathrm{Km}^{2}\right)$ : 3.258,325; densidade demográfica (hab/ $\left.\mathrm{Km}^{2}\right): 1,93$. (IBGE, 2010).

\section{OBJETIVO GERAL}

Descrever os problemas ambientais durante seu trajeto do córrego Arroz Doce.

\section{OBJETIVO ESPECÍFICO}

> Verificar a falta de água em algumas propriedades no córrego Arroz Doce

> Fazer uma analise dos dados obtidos, através do mapeamento da área de estudo, abordando os itens: uso da terra e cobertura vegetal, hipsometria e clinográfico.

\section{METODOLOGIA}

Trabalho de campo foi realizado in locu com câmera digital (Samsung) 3.2, percorrendo, desde sua nascente, na fazenda Santana que fica aproximadamente $25 \mathrm{~km}$, da cidade de Selvíria, que possui uma reserva de mata, de 45 hectares onde nasce o córrego Arroz Doce, e passando por várias outras pequenas propriedades até desaguar, 
no Rio Paraná. Durante o trajeto foram tiradas fotos da vegetação desde sua nascente até desaguar no Rio Paraná. Depois foram feitos trabalhos de gabinetes, junto ao Programa de Pós-Graduação em Geografia no LABORAM/UFMS/CPTL (Laboratório de Análise de Estudos Ambientais), as figuras reveladas, foram interpretadas, com auxilio de outros trabalhos, desenvolvidos nesta área, com imagens baixadas através do site do INPE (www.inpe.br).

Para elaboração das imagens foram trabalhadas no Software Spring® 5.1.5., esta etapa consistiu na manipulação de imagens digitais da série Landsat (Land Remote Sensing Satellite) 5 sensor TM (Thematic Mapper) adquiridas através de downloads no site www.dgi.inpe.br. que se encontram disponíveis gratuitamente.

Após aquisição das imagens no formato TIFF, as mesmas foram convertidas para o formato compatível no Spring® 5.1 .5 no módulo Impima 5.1.5, extensão do software Spring® ${ }^{\circledR} .1 .5$, e tem como função, converter as imagens adquiridas para manipulação no software. A conversão da Imagem TIFF foi efetuada no Impima 5.1.5, a manipulação o processamento e tratamento no software Spring® 5.1 .5 e finalização no CorelDRAW. X5 responsável pela finalização do layout do mapa. Para o tratamento das imagens no software Spring® 5.1 .5 foi efetuado após a criação do projeto no banco de dados disponível no site www.inpe.br.

Para importar as imagens é necessário escolher as bandas no qual será realizado o tratamento no software. Sendo assim é importante conhecer as funções de imageamento espectral de cada banda do satélite no qual se esta trabalhando (Landsat 5 sensor TM) e escolher as bandas no qual se terá a melhor "assinatura espectral", representação da superfície terrestre, da área escolhida. Segundo Paranhos Filho et al (2008), os tipos de cobertura no solo, absorve porções específicas do espectro eletromagnético, o que diferencia as respostas espectrais, resultando em uma "assinatura espectral" para cada tipo de cobertura do solo

No satélite Landsat 5 sensor TM o número de bandas somam um total de 7. Sendo definido importar as bandas 3, 4 e 5, para tratamento no software, pois estas permitem uma boa identificação de vegetações e manchas urbanas (banda 3), limite de corpos de água, drenagens e áreas agrícolas (banda 4) e umidade do solo e vegetação (banda 5). 


\section{RESULTADOS E DISCUSSÕES}

O município de Selvíria localiza-se na porção Leste do Estado, nas Latitudes de 20ำ 22' 26"S e Longitude 51 40' 35"' W. (Figura 1).

Segundo Köppen o clima característico é o denominado Aw, apresentando inverno seco e chuvas máximas de verão. A precipitação pluviométrica anual varia entre 1750 a 2000 mm anuais, excedente hídrico anual de 1200 a 1400 mm durante 07 a 08 meses de deficiência hídrica de 200 a 350 mm durante 03 meses. (SEPLAN, 1990).

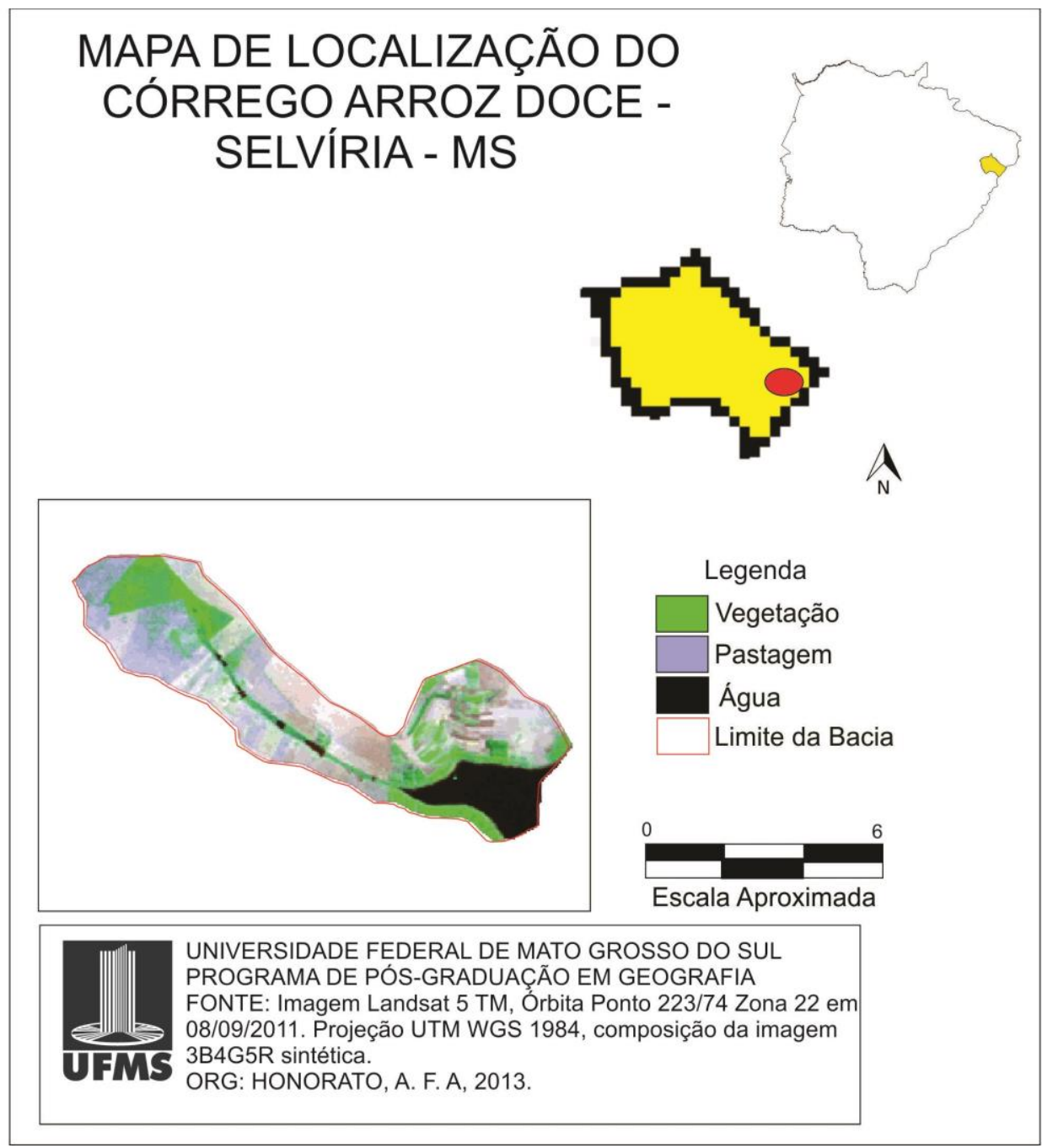

Figura 1: Mapa de Localização do Córrego Arroz Doce - Selvíria/MS. 


\section{Hipsometria do Córrego Arroz Doce}

O relevo do Córrego Arroz Doce é representado a partir das curvas hipsométricas, obtidas a partir da imagem de radar SRTM, e auxilio da carta topográfica de Aparecida do Tabuado folha SF.22-V-B-III (Ministério do Exército). Estas estão distribuídas em cotas com equidistâncias de curvas de nível de 40 metros, que variam entre 220 a 425 metros aproximadamente. Na Figura 2 encontra-se a representação do mapa hipsométrico do córrego Arroz Doce.

\section{MAPA HIPSOMÉTRICO DO CÓRREGO ARROZ DOCE SELVÍRIA - MS}

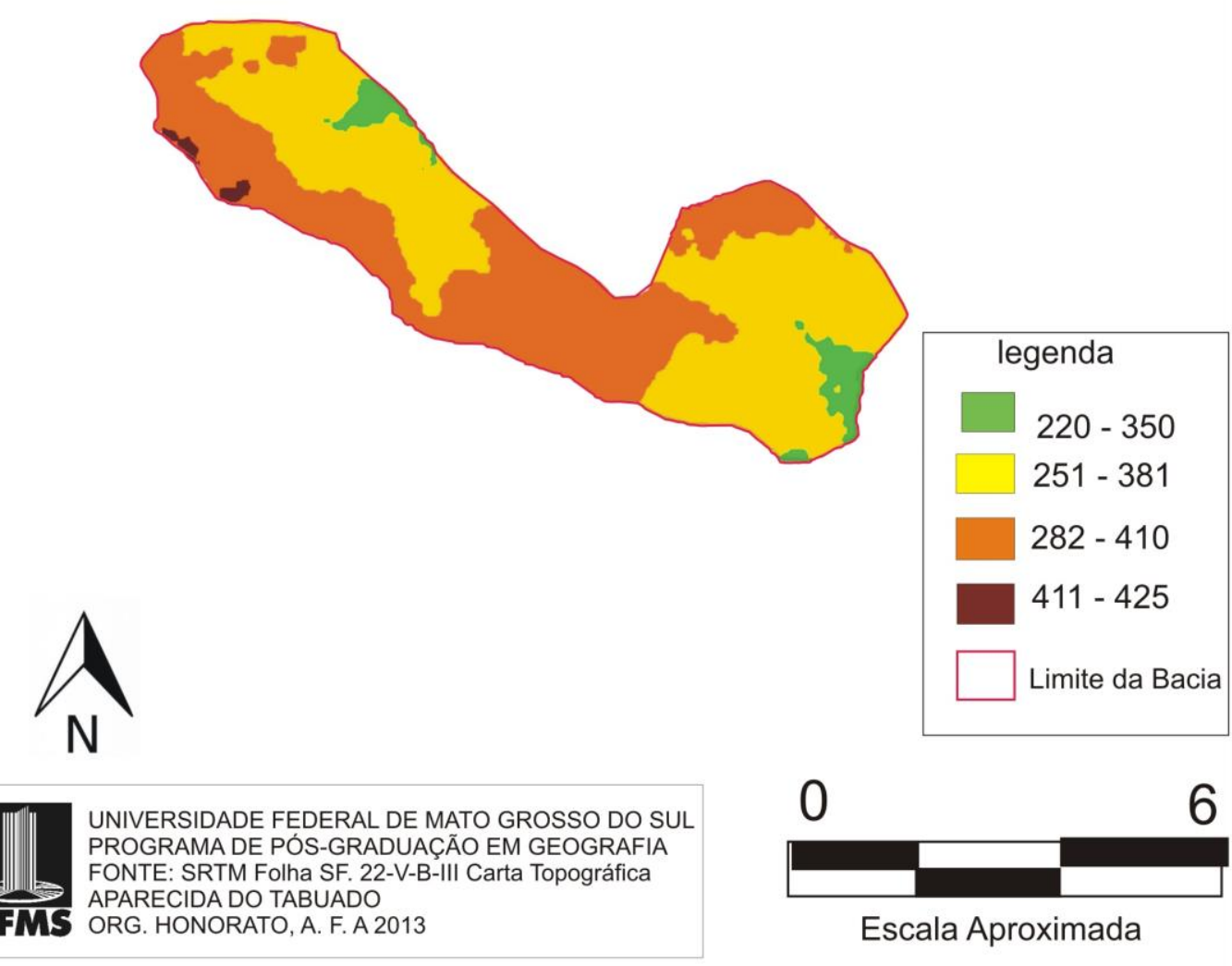


Figura 2 - Mapa de Hipsométrico do córrego Arroz Doce - Selvíria/MS.

\section{Clinográfico do Córrego Arroz Doce}

O Mapa clinográfico representa a declividade do Córrego Arroz Doce. De acordo com mapa, mostra-nos que a bacia do córrego Arroz Doce é uma área plana de pouca declividade.

O Córrego Arroz Doce apresentou uma declividade de 0 a 16\% em quase toda sua bacia. Sendo que a bacia como um todo, sua declividade é de 0 a $24 \%$ conforme mostra a figura 3.

\section{MAPA CLINOGRÁFICO DO CÓRREGO ARROZ DOCE SELVÍRIA - MS}

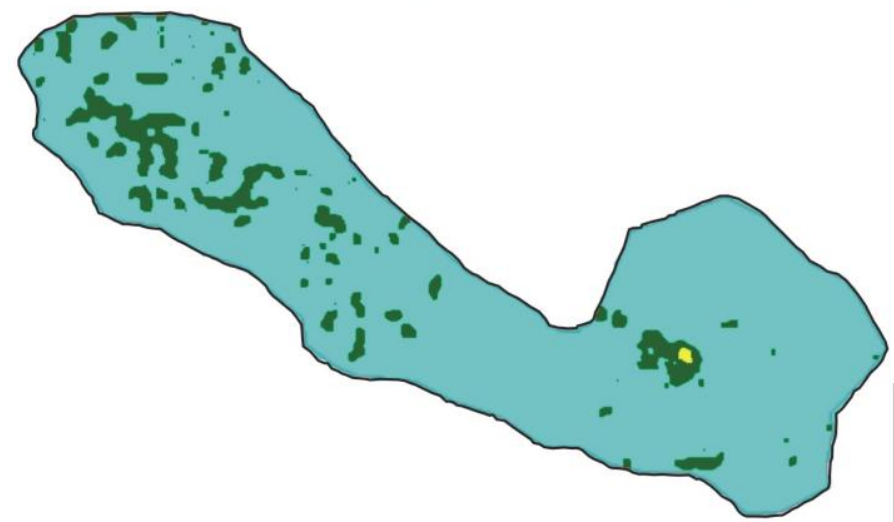

Legenda
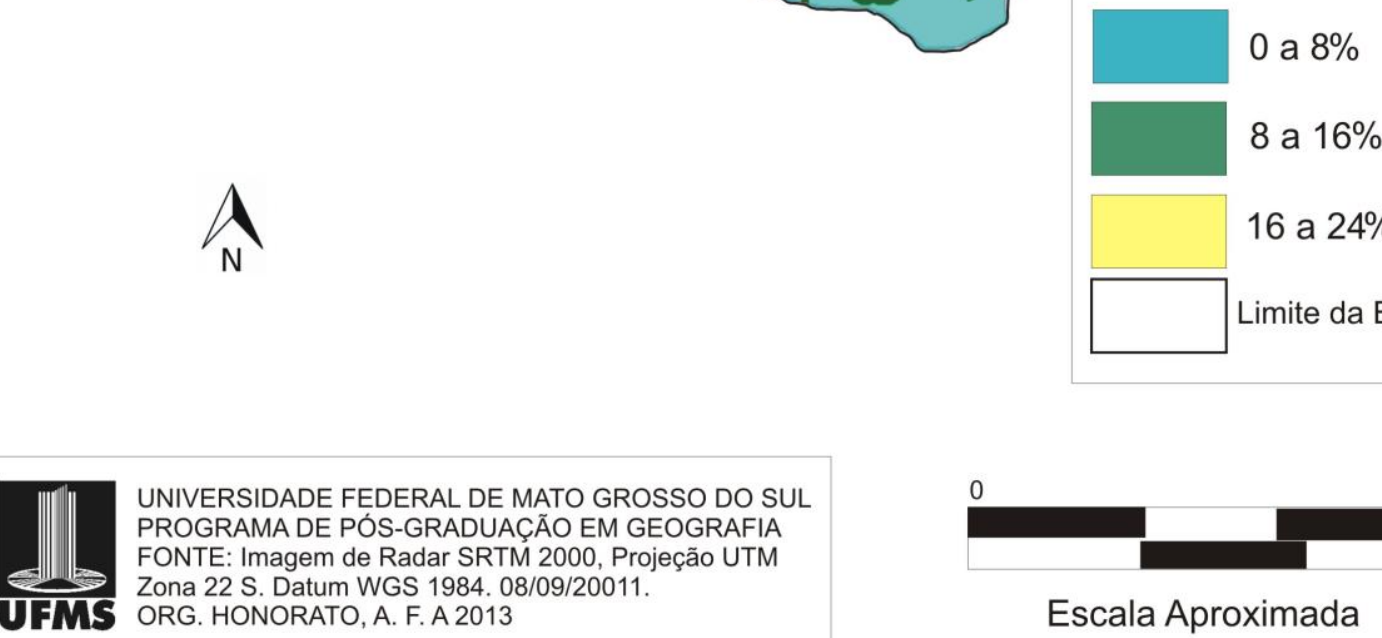

UNIVERSIDADE FEDERAL DE MATO GROSSO DO SUL PROGRAMA DE PÓS-GRADUAÇÃO EM GEOGRAFIA FONTE: Imagem de Radar SRTM 2000, Projeção UTM Zona 22 S. Datum WGS 1984. 08/09/20011. ORG. HONORATO, A.F.A2013

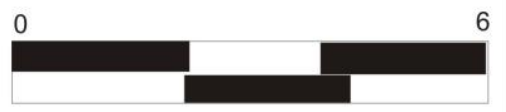

Escala Aproximada 
Figura 3 - Mapa Clinográfico córrego Arroz Doce - Selvíria/MS.

\section{Uso da Terra e Cobertura Vegetal do Córrego Arroz Doce}

O Mapa de Uso da Terra e Cobertura Vegetal foi desenvolvido a partir da imagem de satélite Landsat 5 TM de 08/09/2011. Através da imagem foi possível identificar o uso de pastagem, para a atividade agropecuária, não há presença de mata ciliar entorno do córrego, somente a presença, de mata, numa área próxima de sua nascente.

A área que está inserida o córrego Arroz Doce, encontra-se em um processo de alteração ambiental, devido ao uso excessivo e intensivo de atividades ligadas à pecuária (Figura 4).

\section{MAPA USO DA TERRA E COBERTURA VEGETAL DO CÓRREGO ARROZ DOCE SELVÍRIA - MS}

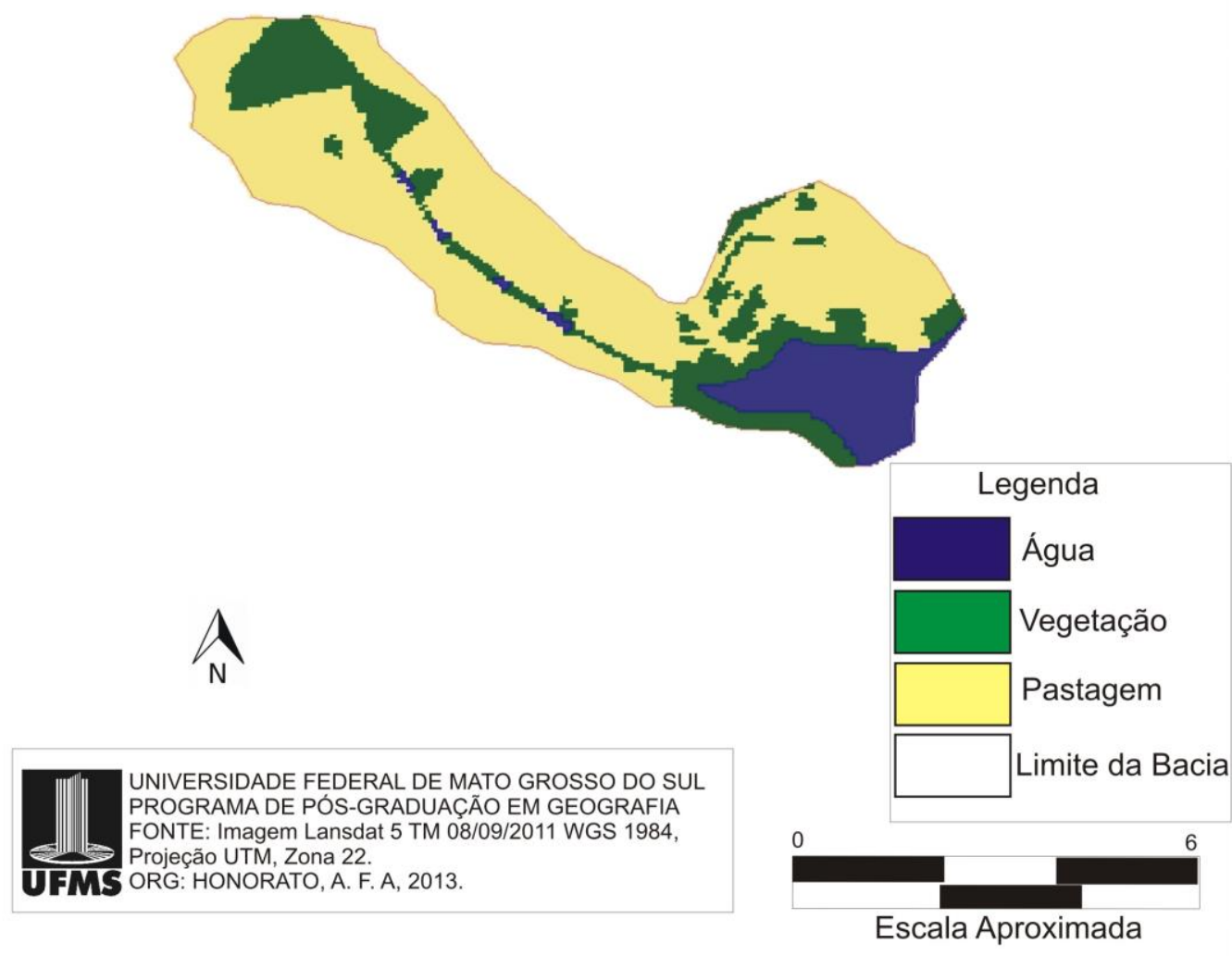

Figura 4 - Mapa de uso e ocupação da bacia do córrego Arroz Doce - Selvíria/MS. 
O local tem como principal uso a de pastagem, segundo (Bertoni \& Lombardi Neto, 1990), pastoreio excessivo afeta no vigor das plantas, proporcionando seu declínio e morte. Proporciona também um solo descoberto de vegetação acelerando com isso erosões, deixando o solo menos fértil.

$\mathrm{Na}$ visita feita em campo foi possível comprovar o que foi apresentado nas imagens de satélite Landsat 5 TM. Há imensa área de pastagem, vegetação esparsa, e um dos principais problemas a falta de planejamento adequado para a utilização da bacia hidrográfica do córrego Arroz Doce. (quadro 1: Fotos tiradas da área de estudo).

Em geral as zonas rurais possuem áreas de interesse para a preservação ambiental com importantes mananciais hídricos, nascentes, cursos de água, maciços vegetais, solos agriculturáveis, dentre outros recursos naturais. Sendo importante qualificar a diversidade e as condições de preservação desses recursos e, em caso de deterioração, a capacidade de recomposição de maciços vegetais, matas ciliares. (BRASIL, Plano diretor participativo, 2005).

O planejamento ambiental é utilizado quando se deseja, principalmente, mobilizar pessoas para ações relacionadas à conservação e preservação ambiental. De acordo com Sorrentino et al, 2005) devem ser direcionados para a cidadania ativa considerando o sentido de pertencimento e coresponsabilidade que, por meio da ação coletiva e organizada, busca a compreensão e superação das causas estruturais e conjunturais dos problemas ambientais. 


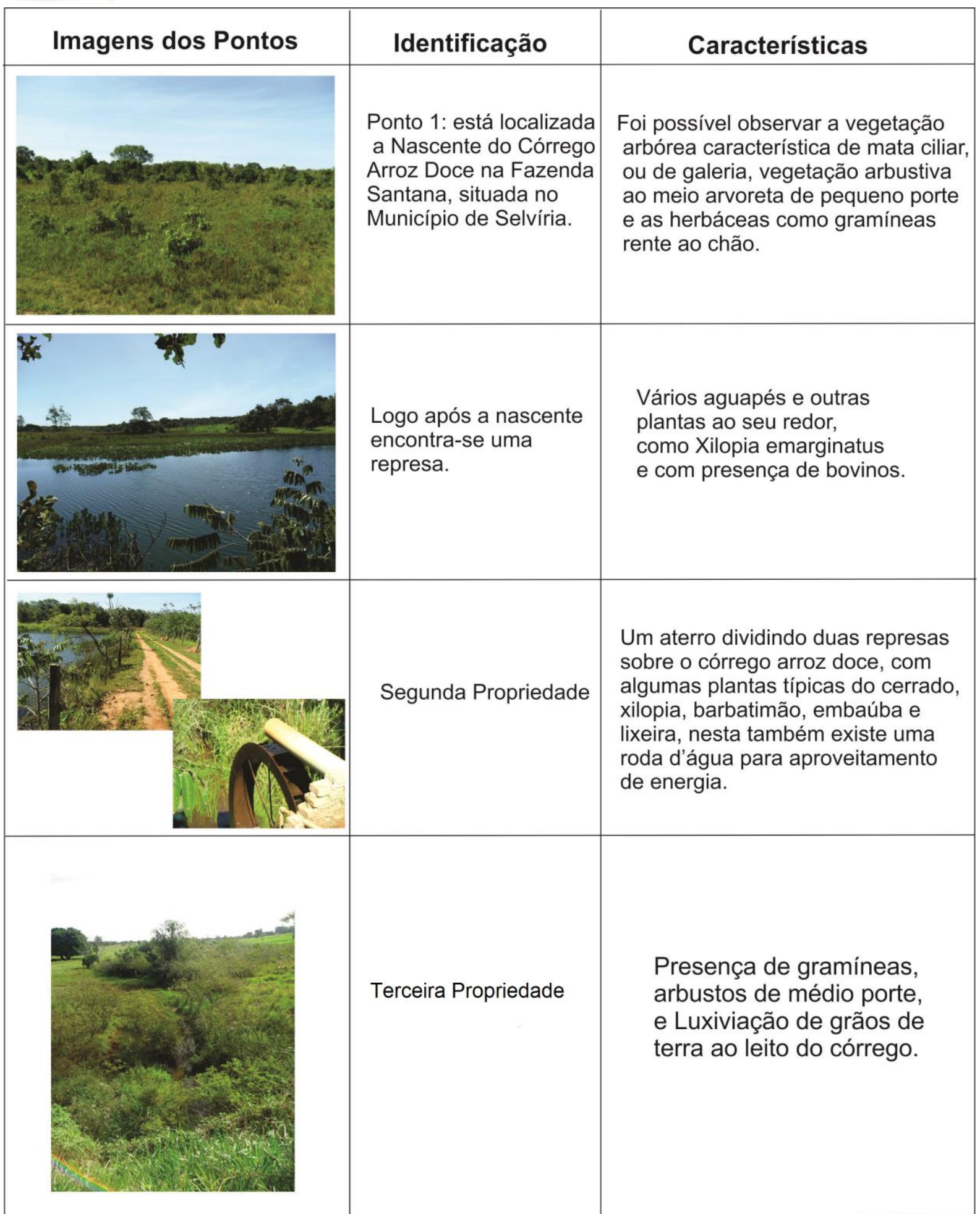

Quadro 1: Fotos Tiradas da área de Estudo. Córrego Arroz Doce - Selvíria/MS.

As fotos ressalta o que foi identificado através das imagens de satélite Landsat $5 \mathrm{TM}$, que o uso para pastagens e a pouca vegetação nas proximidades do córrego Arroz Doce. O que nos mostra que necessita de planejamento ambiental urgente, ou vários sitiantes 
acabarão sem água para seus fins. Como observamos em uma das fotos, apenas um reguinho de água (quadro 2: Fotos tiradas da área de estudo).

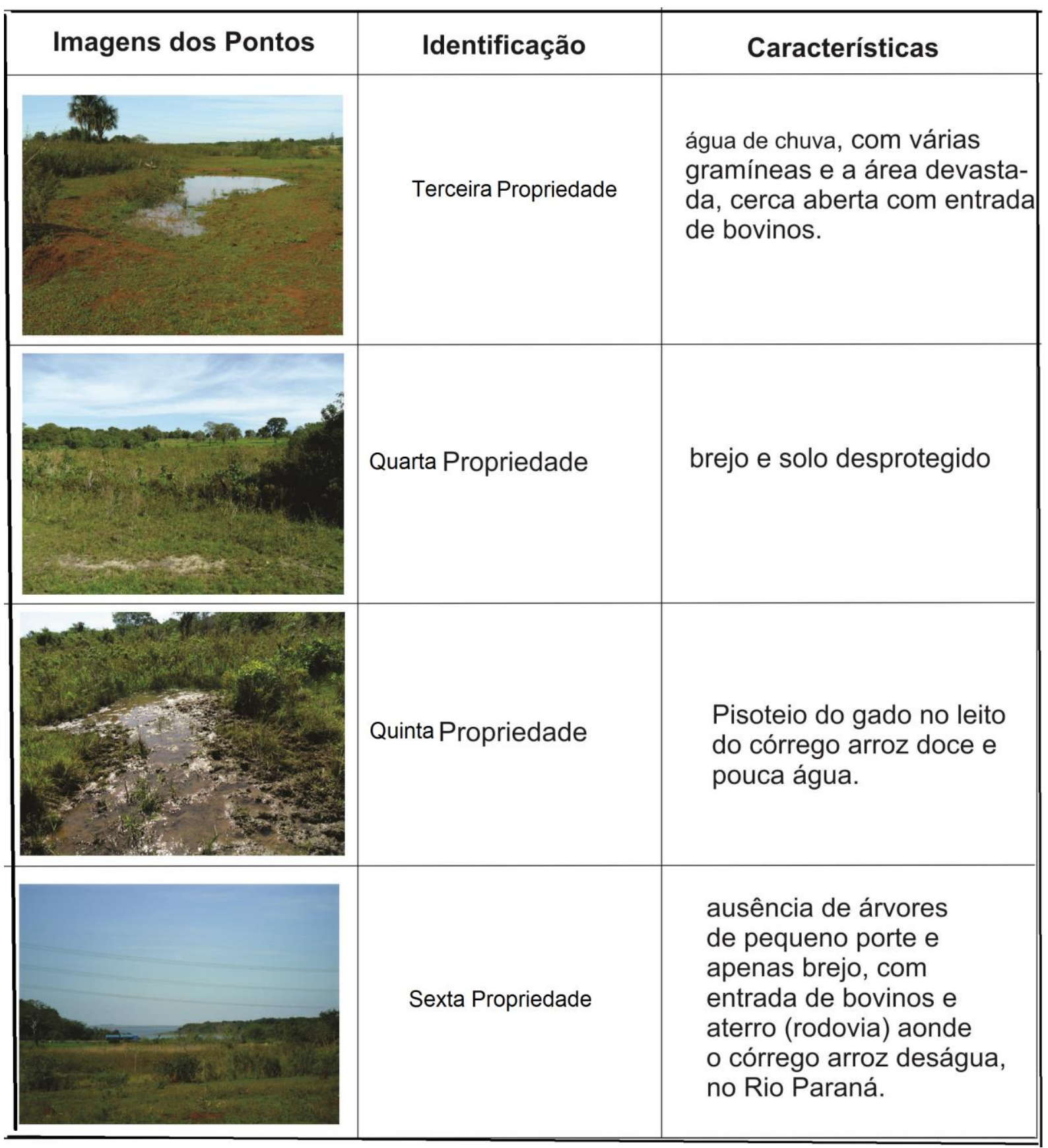

Quadro 2: Fotos Tiradas da área de Estudo. Córrego Arroz Doce - Selvíria/MS. 
Na tabela 1 abaixo estão os tipos de plantas identificadas na nascente e durante o curso do córrego Arroz Doce.

\begin{tabular}{|l|l|}
\hline Jatobá & Hymenaea courbaril \\
\hline Cega machado & Physocalymma sacaberrimum Pohl \\
\hline Sambaíba & Curatella americana \\
\hline Barbatimão & Stryphnodendron adstringens \\
\hline Ingá & Inga edulis \\
\hline Angico vermelho & Anadenanthera peregrina \\
\hline Pau de pombo & Matayba elaegnoides \\
\hline Olho de cabra & Osmosia arborea \\
\hline Embaúba branca & Cecropia hololeuca Miq \\
\hline Coco Babaçu & Orrbignya speciosa \\
\hline Goiabeira & Psidium Guayaba \\
\hline Jenipapo & Genipa americana L \\
\hline Marmelinho do Campo & Alibertia sessilis \\
\hline Piper & Piper nigrum \\
\hline Miconia & Miconia albicans \\
\hline Macaúba & Acrocomia Aculeata \\
\hline Candeia & Moquinia polymorpha (Less.) \\
\hline Chicha & Sterculia chicha St. Hil. ex Turpin \\
\hline Buriti & Mauritia flexuosa \\
\hline Pimenta de Macaco & Xylopia aromática \\
\hline Tucum-do-brejo & Bactris setona \\
\hline Junco & Juncus effusus \\
\hline Andropogon & Andropogon gayanus \\
\hline Sempre viva & Eriocaulon Paepalanthus \\
\hline & \\
\hline & \\
\hline
\end{tabular}

Tabela 1- Listagem das principais espécies encontradas no local de estudo, na nascente, e durante todo trajeto do córrego do Arroz Doce.

Verifica-se que na nascente do corrego, ainda existe várias espécies de mata ciliar, é necessário um cercamento, pois foram vista animais bovinos na área.

Em algumas propriedades, observa-se a ausência de algumas especies do mata ciliar e presença de represa, ao qual desviam o leito do córrego, ocorrendo a falta de água, sendo necessário um plano de ação para a área . 


\section{Perfis Topográficos do Córrego Arroz Doce}

Com base nos perfis topográficos observa-se que a nascente do córrego Arroz Doce inicia aproximadamente a $380 \mathrm{~m}$, de altitude sendo o ponto mais alto do canal do córrego e nas proximidades dos $380 \mathrm{~m}$ (Perfil transversal próximo da área da nascente), chegando até a 330m (perfil transversal próximo da área da foz), aproximado em direção à foz.

No quadro 3 mostra-se os perfis topográficos do Córrego Arroz Doce, sendo 2 perfis transversais (Próximo da Nascente e próximo da Foz)

\section{Perfis Transversais}

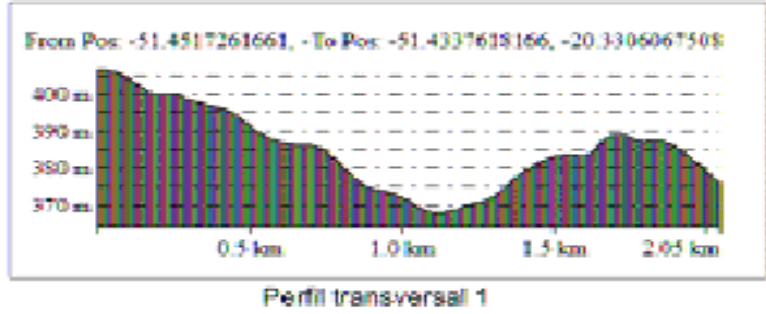

Penti transargal 1

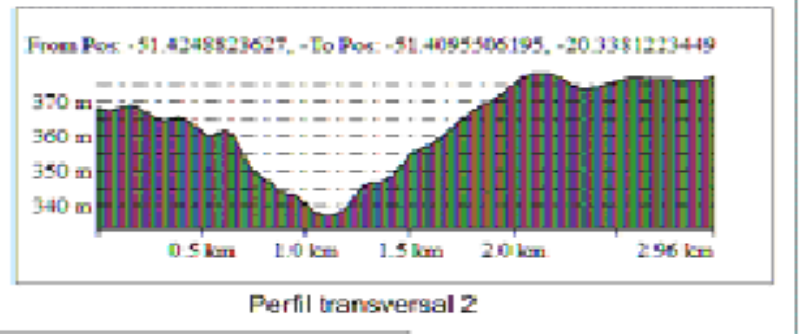

Perfil transwergal 2

Quadro 3. Perfis Topográficos do Córrego Arroz Doce - Selvíria/MS.

\section{CONCLUSÃO}

A contribuição desse trabalho foi entender que com a ajuda de novas tecnologias como geoprocessamento e georreferenciamento são importantes para realizarem uma análise do local da pesquisa. Pode-se concluir que, no trajeto do córrego Arroz Doce desde a nascente no município de Selvíria, de que a interferência do homem e o resultado das transformações ao longo do tempo houve uma eutrofização dos elementos naturais no seu trajeto, sendo viável um planejamento de recuperação do córrego uma vez que o mesmo serve de abastecimento a várias propriedades. 


\section{REFERÊNCIAS BIBLIOGRÁFICAS}

BERTALLANFY, L. V. Teoria Geral dos Sistemas. Petrópolis: Editora Vozes, 1977.

BRASIL. Ministério das cidades. Plano diretor participativo: guia para elaboração pelos Municipios e cidadãos. 2 Edição. ROLNIK, Raquel; PINHEIRO M. Otilie- Brasília: Ministério das Cidades; Confea, 2005. 160p.

CHRISTOFOLETTI, Antonio. Modelagem de sistemas ambientais. São Paulo: Edgard Blücher Ltda, 236 p., 1999, 256p.

GUERRA, A. J. T \& CUNHA, S. B. (Org.). Geomorfologia e Meio Ambiente.

IBGE - .http://www.ibge.com.br/cidadesat/painelpainel.php/codmun=500780\&search=matogrosso-do-sul|selviria\#thistorico). Acessado em 10/07/2013.

INPE - WWW.dgi.inpe/cdsr acesso em 10/06/2013.

PARANHOS FILHO, Antonio Conceição; LASTORIA, Giancarlo \& TORRES, Thais Gisele. Sensoriamento Remoto Ambiental Aplicado: introdução às geotecnologias. Campo Grande, MS: Ed. UFMS, 2008. 198p.

SEPLAN, Atlas Multirreferencial. Secretaria de Planejamento e Coordenação Geral, Fundação IBGE, 1990.

SILVA, João dos Santos Vila da. Análise Multivariada em Zoneamento para Planejamento Ambiental Estudo de Caso: bacia hidrográfica do alto rio Taquari MS/MT. Tese de Doutorado em Engenharia Agrícola do Programa de Pós Graduação em Engenharia Agrícola da Universidade Estadual de Campinas, 2003. 307p. Disponível em: http://docsagencia.cnptia.embrapa.br. Acesso em: 10 de Agosto de 2013.

SORRENTINO, M. ; TRAJBER, R. ; MENDONÇA, P. ; FERRARO JUNIOR, L. A . 2005. Educação Ambiental como Política Pública. Educação e Pesquisa, São Paulo, v. 31, n. 2, p. 285-299. Disponível em: http://www.scielo.br//v31n2/a10v31n2.pdf. Acesso em Março de 2012.

TEIXEIRA,Wilson; et al.Decifrando a Terra. São Paulo: Oficina de textos p. 196. 2000, 588p. 